\title{
Low-Cost, Energy-Saving Plasma Method for Preparation of Inorganic Submicron Fibers
}

\author{
Veronika Medvecká ${ }^{1}$, Dušan Kováčik ${ }^{1}$, Anna Zahoranová1, Mirko Černák ${ }^{1,2}$ \\ ${ }^{1}$ Department of Experimental Physics, Faculty of Mathematics, Physics and Informatics, Comenius University \\ Mlynská dolina F2, 84248 Bratislava, Slovakia \\ medvecka@fmph.uniba.sk ; kovacik@fmph.uniba.sk; zahoranova@fmph.uniba.sk \\ ${ }^{2}$ CEPLANT, Department of Physical Electronics, Faculty of Science, Masaryk University \\ Kotlářská 2, 61137 Brno, Czech Republic \\ cernak@physics.muni.cz
}

\section{Extended Abstract}

Inorganic ceramic fibers $\left(\mathrm{Al}_{2} \mathrm{O}_{3}, \mathrm{SiO}_{2}, \mathrm{TiO}_{2}, \mathrm{ZnO}\right.$, etc. $)$ are one of the most studied materials in the submicron region. They are usually prepared by thermal calcination of composite metal-organic fibers [1-3]. The basis of these composite fibers is the carrier polymer material - base polymer and precursor serving as a source of inorganic material. Composite organometallic fibers are prepared from this "cocktail" using standard spinning techniques (electrospinning, forcespinning, chemical spinning) [4,5]. Then, the composite fibers are transformed to ceramics by heat treatment in the process of thermal calcination. Thermal calcination is used for removing the organic base polymer by the preparation of inorganic submicron fibers. It proceeds at high temperature $\left(500-1000^{\circ} \mathrm{C}\right)$ for several hours $(5-10 \mathrm{hrs})$. Due to the high temperature approach and long treatment times, conventional thermal calcination needed by the processing of inorganic submicron fibers is significantly time- and energy-consuming process.

Recent research is focused on the searching for the procedures to prepare inorganic fibers by simpler, low temperature and economic way. The use of plasma is one of the potential alternatives [6]. Plasma technologies are successfully replacing a number of processes in many fields of industry. With a large number of parameters by which the properties of plasma can be customized for a required purpose, it is an ideal tool for the removal of the organic polymer at room temperature in a relatively short time [7-10].

In this work we study the plasma assisted calcination of various types of submicron composite fibers by using Diffuse Coplanar Surface Barrier Discharge (DCSBD) [11,12]. The effect of plasma on the composite fibers comprising two types of polymers and several types of precursors prepared by two different spinning techniques (electrospinning and forcespinning) was examined in terms of the organic polymer removal using several of surface diagnostic techniques (Fourier Transform Infrared Spectroscopy - FTIR, Energy-dispersive X-ray spectrometry - EDX, X-ray Photoelectron Spectroscopy - XPS). The influence of plasma on the morphology of the fibers was investigated by Scanning Electron Microscopy (SEM) and X-ray diffraction (XRD). The samples were also studied using the CHNS analysis to determine the total carbon content and thermogravimetric analysis to investigate the changes in the thermal degradation of organic material. Effect of plasma treatment has been studied as a pre-treatment in total calcination. The output fibers have been studied in terms of elemental composition and crystalline structure.

The observed fast removal of organics within short exposure times (less than 1 hour) and low temperature approach (approx. 50-60 ${ }^{\circ} \mathrm{C}$ ) makes the plasma assisted calcination using DCSBD an advantageous alternative to conventional thermal calcination for preparation of inorganic fibers and allows the use of wider range of materials and substrates sensitive to high temperature. As a pre-treatment method it can be used for significant shortening of the conventional calcination process duration and can significantly decrease the energetic requirements of the whole process. Diffuse character and macroscopically homogeneous plasma even without the need of any expensive noble working gas, generated by DCSBD, is applicable for the production of inorganic fibers in the submicron range without damage of their fibrous structure. In addition, the increase in porosity of fibers was observed, which is very beneficial in applications requiring large surface-to-volume ratio. 


\section{References}

[1] J. Y. Park and S. S. Kim, "Effects of processing parameters on the synthesis of TiO2 nanofibers by electrospinning," Met. Mater. Int. vol. 15, pp. 95-99, 2009.

[2] P. K. Panda and S. Ramakrishna, "Electrospinning of alumina nanofibers using different precursors," J. Mater. Sci. vol. 42, pp. 2189-2193, 2007.

[3] K. Starbova, D. Petrov, N. Starbov, and V. Lovchinov, "Synthesis of supported fibrous nanoceramics via electrospinning," Ceram. Int. vol. 38, pp. 4645-4651, 2012.

[4] S. Ramakrishna, K. Fujihara, W.-E. Teo, T.-C. Lim, and Z. Ma, An Introduction to Electrospinning and Nanofibers, National University of Singapore, Singapore, 2005.

[5] B. Raghavan, Y. Ner, G. Stinson, E. Peno, C. Gomez, and K. Lozano, "Forcespinning TM : An important advancement in Nanofibers Production," pp. 1-5, 2012.

[6] Y. Li, P. Kuai, P. Huo, and C. Liu, "Fabrication of $\mathrm{CuO}$ nanofibers via the plasma decomposition of $\mathrm{Cu}(\mathrm{OH}) 2$," Mater. Lett. vol. 63, pp. 188-190, 2009.

[7] J. M. Gomez-Vega, K. Teshima, A. Hozumi, H. Sugimura, and O. Takai, "Mesoporous silica thin films produced by calcination in oxygen plasma," Surf. Coatings Technol. vol. 169-170, pp. 504-507, 2003.

[8] A. Palaniappan, J. Zhang, X. Su, and F. E. H. Tay, "Preparation of mesoporous silica films using sol-gel process and argon plasma treatment," Chem. Phys. Lett. vol. 395, pp. 70-74, 2004.

[9] H. Wang, H. Tang, J. He, and Q. Wang, "Fabrication of aligned ferrite nanofibers by magnetic-field-assisted electrospinning coupled with oxygen plasma treatment," Mater. Res. Bull. vol. 44, pp. 1676-1680, 2009.

[10] P. Baroch, J. Hieda, N. Saito, and O. Takai, "Atmospheric plasma-calcination of mesoporous tungsten oxide utilizing plasma dielectric barrier discharge," Thin Solid Films vol. 515, pp. 4905-4908, 2007.

[11] M. Černák, D. Kováčik, J. Ráhel', P. St’ahel, A. Zahoranová, J. Kubincová, A. Tóth, and L. Černáková, "Generation of a high-density highly non-equilibrium air plasma for high-speed large-area flat surface processing," Plasma Phys. Control. Fusion vol. 53, pp. 124031, 2011.

[12] M. Černák, L. Černáková, I. Hudec, D. Kováčik, and A. Zahoranová, "Diffuse coplanar surface barrier discharge and its applications for in-line processing of low-added-value materials," Eur. Phys. J. Appl. Phys. vol. 47, no. 2, pp. 1-6, 2009. 